\title{
Artikel
}

\section{Is de legitieme portie nog legitiem?}

\author{
Mr. dr. J.H.M. ter Haar*
}

\section{Inleiding}

Onlangs verscheen het rapport Legitieme portie, dat tot stand is gekomen in een samenwerking van het Centrum voor Notarieel Recht van de Radboud Universiteit Nijmegen en Netwerk Notarissen. ${ }^{1}$ Bedoeling van het onderzoek is om met een peiling 'de sfeer rondom de beleving van de legitieme portie te kunnen proeven'. De onderzoekers willen de cijfers laten spreken en geven aan slechts een algemene conclusie te trekken op basis van die cijfers. Daarnaast wordt op basis van een onderzoek in wetsgeschiedenis en literatuur een achtergrond geschetst. Hiermee beogen de onderzoekers de lezer in staat te stellen een weloverwogen keuze te maken betreffende het vraagstuk of de legitieme portie, zoals deze sinds 2003 is vormgegeven, een wenselijk instituut is. De conclusie van de onderzoekers is dat de legitieme portie kan worden afgeschaft. De reden is volgens hen dat de peiling uitwijst dat het grootste deel van het Nederlands publiek de legitieme portie niet wenst te handhaven of niet ongewijzigd wenst te handhaven.

De onderzoekers breken een lans voor meer testeervrijheid en zetten daarbij stevig de toon. Het is echter de vraag of het onderzoek deze aanbeveling rechtvaardigt, temeer omdat uit de peilingen ook blijkt dat een groot deel van het Nederlands publiek de legitieme portie juist omarmt. Daarop ga ik in deze bijdrage nader in.

* Mr. dr. J.H.M. ter Haar is universitair docent Notarieel recht aan de Rijksuniversiteit Groningen.

1. F. Schols \& L. van der Geld, Rapport Legitieme portie, een eerstelijns - en nader voort te zetten - veldonderzoek naar de wenselijkheid van de legitieme portie in het hedendaagse erfrecht, CNR, RUN/Netwerk Notarissen 2021 (hierna: Rapport).

\section{Aanleiding}

De aanleiding voor het onderzoek is volgens de onderzoekers dat er sinds de inwerkingtreding van het erfrecht een beweging in het denken over de legitieme valt waar te nemen. Genoemd wordt de afschaffing van de legitieme portie op Sint Maarten en Curaçao in respectievelijk 2012 en 2014, het feit dat een politieke partij (D66) de afschaffing in 2017 opnam in haar verkiezingsprogramma, en cijfers uit de monitor van Netwerknotarissen (2015 en 2016) waaruit blijkt dat kinderen onterfd worden vanwege het ontbreken van contact. Heel indrukwekkend zijn deze signalen niet. D66 heeft zich immers al voor de invoering van het huidige erfrecht kritisch opgesteld ten opzichte van de legitieme portie, zo blijkt ook uit de parlementaire geschiedenis bij de totstandkoming van het huidige erfrecht. ${ }^{2}$ Dat op Curaçao en Sint Maarten de legitieme portie is afgeschaft, is weliswaar opmerkelijk, maar meer indruk maakt inmiddels het feit dat de legitieme portie in België bij de laatste modernisering van het erfrecht in 2018 juist is gehandhaafd. Daarbij zij opgemerkt dat de Belgische legitieme portie evenals in ons recht is afgezwakt van een goederenrechtelijke aanspraak naar een geldvordering. ${ }^{3}$ De cijfers van Netwerknotarissen die indiceren dat meer ouders kinderen onterven vanwege het ontbreken van contact, zijn vooral verontrustend. Over het denken over de legitieme portie zeggen deze cijfers weinig. De legitieme portie staat immers aan onterving niet in de weg en is mogelijk juist een welkome pleister op de wond van het onterfde kind. Ik kom hier in deze bijdrage later op terug.

2. Zie o.a. Parl. Gesch. Inv. Boek 4 BW, p. 1804. Afschaffing van de legitieme portie is overigens geen onderdeel van het verkiezingsprogramma 2021-2025 van D66, Een nieuw begin, zie www.D66.nl.

3. Zie hierover W.D. Kolkman, Belgisch Erfrecht grondig herzien, TE 2018, afl. 4, p. 79-85. 
Hoewel op de aanleiding voor het onderzoek het een en ander valt af te dingen, kan een peiling naar het gevoelen rondom het instituut interessante informatie opleveren. De maatschappij is constant in beweging, zo (mogelijk) ook het denken over een fenomeen als de legitieme portie.

\section{De legitieme portie}

De legitieme portie hangt samen met het bijzondere karakter van de afstammingsband tussen ouders en kinderen. Aan deze afstammingsband wordt in de wet op verschillende wijzen invulling gegeven. Zo ontleent een kind zijn geslachtsnaam en nationaliteit aan zijn ouders. Ouders zijn jegens het kind tot 21 jaar, ongeacht hun behoeftigheid, onderhoudsplichtig. $\mathrm{Na}$ het 21ste levensjaar is de onderhoudsplicht in geval van behoeftigheid wederkerig. Een van de belangrijkste juridische gevolgen van de afstammingsband is dat een kind versterferfgenaam is van zijn ouders en dat ouders hun kinderen niet iedere erfrechtelijke aanspraak kunnen ontzeggen.

Sinds 1 januari 2003 is de legitieme portie geen erfdeel meer, maar slechts een aanspraak op geld. De onterfde legitimaris is op voorhand 'uitgeboedeld'. Daarmee is de legitimaris nauwelijks nog een stoorzender in de afwikkeling van de nalatenschap. De legitieme portie valt door aanpassing van het breukdeel meestal lager uit dan voorheen. Voor zover deze ten laste komt van de langstlevende partner van de erflater kan hij er in zijn testament voor zorgen dat zij gedurende zijn/haar leven niet opeisbaar is. De legitimaris moet zich zelf bij de erfgenamen of executeur melden, hij krijgt van zijn onterving of recht op een legitieme portie van hen geen bericht. Vijf jaar na het overlijden van de ouder vervalt zijn wilsrecht.

In vergelijking met het oude erfrecht stelt de legitieme portie niet meer zoveel voor, zo erkennen ook de onderzoekers. ${ }^{4}$ Wie een kind wil onterven, maar moeite heeft met de legitieme portie, kan zelfs zijn toevlucht nemen tot creatieve estateplanners die de nodige manieren kennen om de legitimaire aanspraak van het onterfde kind zo veel mogelijk illusoir te maken. Desalniettemin mag men de legitieme portie nog steeds niet onderschatten. Het kan wel degelijk gaan om een substantieel bedrag. ${ }^{5}$ In ons erfrecht staat testeervrijheid voorop. Ouders mogen hun kinderen zonder opgaaf van redenen onterven. $\mathrm{Zij}$ mogen hun kinderen ook ongelijk behandelen. De beperking van de testeervrijheid van ouders door de legitieme portie (en andere wettelijke rechten) is daarom relatief. Een kind heeft een mogelijkheid om tegen een vergaande benadeling op te komen door zijn legitieme portie in te roepen. Ook het kind hoeft zich voor zijn actie niet te verantwoorden. In dit opzicht trekt de wetgever geen partij. Rechters bemoeien zich niet met het motief van de ouders om hun kind te onterven, maar zij bemoeien zich ook niet met het motief van een kind om de legitieme portie in te roepen. Dat maakt het recht beter hanteerbaar. De verwezenlijking van het recht op een legitieme portie kan buiten de rechter om. In de onderhandelingen rondom de legitieme portie speelt de notaris of erfrechtmediator een bemiddelende rol. Rechtszaken over de legitieme portie richten zich vrijwel alleen nog op de berekening van de aanspraak en de verstrekking van informatie. Het neutrale karakter van de legitieme portie is enerzijds een voordeel en anderzijds een nadeel. Een ouder kan - ook objectief gezien nog zo'n goede reden hebben om een kind zijn erfdeel te ontzeggen, het kind heeft desalniettemin recht op een legitieme portie, tenzij het onwaardig is (art. 4:3 van het Burgerlijk Wetboek; BW).

\section{Het spanningsveld}

Het rapport maakt duidelijk dat de legitieme portie in de parlementaire behandeling van het huidige Boek 4 BW al vroeg onder vuur werd genomen. ${ }^{6}$ Sindsdien is de kritiek van tegenstanders niet verstomd. De beperking van de testeervrijheid wordt voor wat betreft aanspraken van kinderen door de meeste critici als acceptabel gezien waar het gaat om de voorziening in de kosten van levensonderhoud of studie van kinderen tot 21 jaar (of om een beloning voor onbetaalde arbeid). Voor het overige achten zij de beperking excessief, want in strijd met de autonomie van de testateur. Bovendien maakt de legitieme portie het erfrecht complex.

De belangen die met de instandhouding van de legitieme portie zijn gemoeid, zijn minder eenduidig. In de parlementaire geschiedenis zijn verschillende argumenten voor handhaving van de legitieme portie opgeworpen. ${ }^{7}$ Niet alle argumenten die spreken voor de legitieme portie hebben hetzelfde gewicht. Sommige worden breder omarmd dan andere en er wordt erkend dat het gewicht van argumenten in de loop der jaren kan verschuiven. Veel terugkomend is vooral het argument dat de legitieme portie ervoor zorgt dat een barrière wordt opgeworpen tegen ongelijke behandeling van kinderen. Ook wordt genoemd de bij het volk levende rechtsovertuiging dat kinderen een deel van de nalatenschap van hun ouders horen te krijgen. Daarnaast wordt waarde toegekend aan de bescherming van ouders tegen beinvloeding door derden. Ook de verzorgingsbehoefte van kinderen is van belang. De legitieme portie kan een kind een financieel vangnet bieden, zodat het niet hoeft terug te vallen op overheidssteun. Gevreesd wordt ten slotte dat afschaffing van de legitieme portie zou leiden tot een toename van procedures waarin testamenten zouden worden aangevochten. 


\section{Som ineens}

Er bestaat een verband tussen de legitieme portie en de som ineens, die sinds 1 januari 2003 in artikel 4:35 BW te vinden is. Kinderen tot 21 jaar kunnen op deze som ineens aanspraak maken in de nalatenschap van een ouder, voor zover nodig voor hun verzorging en opvoeding, levensonderhoud of studie. De som ineens weerspiegelt de minimale verplichting die ouders in erfrechtelijke zin ten opzichte van hun kinderen hebben. Wie als ouder tijdens het leven een alimentatieplicht heeft ten aanzien van een kind, hoort ook na zijn overlijden te voorzien in een bijdrage aan het levensonderhoud. Dit kan hij doen door de langstlevende onderhoudsplichtige ouder naar vermogen middelen te geven, of door het kind zelf middelen na te laten die aangewend kunnen worden om in de kosten te voorzien. In de rechtsliteratuur lijkt over de rechtvaardiging van de som ineens als inbreuk op de testeervrijheid brede consensus te bestaan. ${ }^{8}$

Het karakter van de som ineens is een andere dan dat van de legitieme portie, al is in beide gevallen sprake van een geldvordering. Zo is de som ineens toegespitst op de werkelijke behoefte van de somgerechtigde van een bepaalde levenscategorie. Dit maakt de som ineens voor de kantonrechter lastig hanteerbaar. Het is immers niet eenvoudig om te beoordelen hoe groot de som ineens zou moeten zijn. Dit zal onder andere afhangen van de vraag of het kind gaat studeren en voor welke studie het dan kiest. Bepaling van de omvang van de som ineens vindt deels plaats met de natte vinger.

Anders dan Van der Geld in de podcast over het onderzoek oppert, hinkt de wetgever met de som ineens naast de legitieme portie niet op twee gedachten. ${ }^{9}$ De som ineens kan immers nodig zijn waar de legitieme portie tekortschiet, zo blijkt uit de parlementaire geschiedenis. ${ }^{10}$ Dit is bijvoorbeeld aan de orde als de legitieme portie ten laste komt van de langstlevende partner van een erflater en daardoor gedurende het leven van deze partner niet opeisbaar is. ${ }^{11}$

In de gerechtelijke praktijk speelt artikel 4:35 BW nauwelijks een rol van betekenis, zo zijn er tot nu tot slechts twee zaken bekend waarin een som ineens door de rechter werd toegekend. ${ }^{12}$

Het bepaalde in artikel 4:35 BW roept verschillende vragen op en verdient herziening, zo menen ook de onderzoekers terecht. ${ }^{13}$ Hopelijk vindt herziening plaats in het kader van het in het door het ministerie in het vooruitzicht gestelde wetsvoorstel met betrekking tot vermo-

8. Zie o.a. W.D. Kolkman, De legitieme portie, WPNR 2019, afl. 7260, p. 803-805 en B. Breederveld, Revisit de legitieme!, FJR 2020/59, maar ook de onderzoekers van het Rapport, zie deel B, par. 4.

9. De podcast is te vinden op www.legitiemeportie.com.

10. Parl. Gesch. Inv. Boek 4 BW, p. 1381.

11. Zie Rb. Amsterdam 30 september 2010, ECLI:NL:RBAMS: 2010:BO8410

12. Over de mate waarin art. 4:35 BW in de testeerpraktijk of bij de boedelafwikkeling, buiten de rechter om, een rol speelt, is weinig bekend.

13. Rapport, deel B, par. 4. gensbeheer bij minderjarigen. ${ }^{14}$ De wenselijkheid van aanpassing van de som ineens staat op zichzelf en is geen wisselgeld voor een eventuele afschaffing van de legitieme portie. Anders dan de onderzoekers stellen, is de som ineens van artikel 4:35 BW dus geen alternatief voor de legitieme portie. Het is een opzichzelfstaand wilsrecht, waarvan het bestaansrecht in de rechtsliteratuur niet wordt betwist, maar dat in de praktijk zelden wordt ingeroepen. Ook na aanpassing zal deze som ineens naar ik inschat in de praktijk een witte raaf blijven.

\section{Protesten en tegengeluiden}

In 2003 is de wetgever zoals hiervoor geschetst in vergaande mate tegemoetgekomen aan de testeervrijheid. In de notariële wetenschap is desalniettemin nog steeds een populair standpunt dat de forfaitaire legitieme portie haar langste tijd heeft gehad en rijp is voor afschaffing. ${ }^{15}$ Op twee fronten kregen de tegenstanders recentelijk een tegengeluid:

a. Allereerst is er de uitspraak van het gerechtshof Amsterdam van 31 juli 2018, ECLI:NL:GHAMS: 2018:2246). Het hof oordeelde dat de legitieme portie niet in strijd is met artikel 1 Eerste Protocol afzonderlijk, noch in samenhang met artikel 14 van het Europees Verdrag tot bescherming van de rechten van de mens en de fundamentele vrijheden (EVRM) en artikel 1 Twaalfde Protocol bij het EVRM. Er is volgens het hof sprake van een 'fair balance' tussen het algemeen belang dat met de legitieme portie is gediend enerzijds en de bescherming van de individuele rechten (lees: het recht op testeervrijheid) anderzijds. De regeling van de legitieme portie kan volgens het hof niet worden gezien als een buitensporige last. ${ }^{16}$ Deze uitspraak is van belang, omdat onder tegenstanders van de legitieme portie meer dan eens is gesuggereerd dat deze in strijd zou zijn met (de strekking van) artikel 1 Eerste Protocol bij het EVRM (het recht op ongestoord

14. Zie onder andere de brief van de Minister voor Rechtsbescherming van 5 december 2019, Kamerstukken II 2019/20, 33836, nr. 47.

15. Het rapport geeft in deel B, par. 9 een uitgebreid overzicht van vooren tegenstanders. Onder de uitgesproken tegenstanders van de huidige legitieme portie bevinden zich met name Kolkman, De legitieme portie, M.J.A. van Mourik, De legitieme portie: weg ermee!, WPNR 1991, afl. 6018, p. 621-625, A.J.M. Nuytinck, Het nieuwe erfrecht van Aruba, Curaçao en Sint Maarten, Tijdschrift voor Antilliaans Recht, TAR-Justicia 2010, afl. 3-4, Asser/Perrick 4 2017/299, B.M.E.M. Schols, De legitieme portie driedimensionaal, abstract, concreet en fiscaal, in: Nieuw erfrecht in de praktijk, een evaluatie (Preadvies KNB), Den Haag: Sdu Uitgevers 2006, F.W.J.M. Schols, Erfrechtelijk chillen op de Antillen, WPNR 2007, afl. 6717, p. 591-597 en Breederveld (die sinds kort aan het rijtje kan worden toegevoegd, zie FJR 2020/59).

16. Tegen het arrest van het hof is cassatie ingesteld, zie HR 14 februari 2020, ECLI:NL:HR:2020:262. De vraag of de legitieme portie strijdig is met art. 1 Eerste Protocol EVRM is daarbij overigens niet aan de Hoge Raad voorgelegd. De klachten die wel zijn voorgelegd, konden niet leiden tot vernietiging van het arrest (art. 81 Wet RO). 
genot van eigendom). ${ }^{17}$ De afschaffing van de legitieme portie in het Caraibisch gebied is blijkens de parlementaire geschiedenis zelfs met name gebaseerd op het idee dat de legitieme portie in strijd zou zijn met artikel 1 Eerste Protocol bij het EVRM. ${ }^{18}$ De onderzoekers sluiten zich aan bij de uitspraak van het hof. ${ }^{19}$ Mijns inziens is dat een goede zaak, omdat de discussie niet op dit niveau thuishoort. Staten hebben op grond van gemelde verdragsbepaling nu eenmaal een ruime mogelijkheid om wetten toe te passen die zij noodzakelijk oordelen om het gebruik van eigendom te reguleren in overeenstemming met (onder meer) het algemeen belang.

b. Het tweede tegengeluid betreft het antwoord van de minister op Kamervragen van de zijde van D66 over het bestaansrecht van de legitieme portie in deze tijd. De minister onderschrijft het belang van de testeervrijheid, maar geeft tegelijkertijd aan dat de testeervrijheid niet onbeperkt is, daarmee doelend op de legitieme portie. De beperking op de testeervrijheid is volgens de minister gebaseerd op de rechtsovertuiging dat aan kinderen en hun afstammelingen een deel van de nalatenschap van hun ouders toekomt. Hij toont zich niet onder de indruk van de stelling dat 'de overgrote meerderheid van de wetenschap' voor afschaffing van de legitieme portie is. De minister heeft er notie van genomen dat uit de uitslag van een peiling van de Koninklijke Notariële Beroepsorganisatie (KNB) blijkt dat $40 \%$ van de ondervraagde Nederlanders voor afschaffing van de legitieme is. Daaruit leidt de minister echter niet af dat op dit moment een dringende en breedgedragen noodzaak wordt ervaren om de legitieme portie af te schaffen. ${ }^{20}$ De minister zag ook geen noodzaak voor nader onderzoek hiernaar, maar toont wel interesse in de te verwachten uitslag van onderhavig Nijmeegs onderzoek.

\section{Relevante ontwikkelingen in de maatschappij}

\subsection{Toename van onterving van kinderen}

In paragraaf 2 gaf ik aan dat de onderzoekers niet duidelijk maken waarom het denken rondom de legitieme portie de laatste jaren mogelijk is veranderd. Wel constateren zij dat het vaker voorkomt dat ouders hun kinderen onterven. Het onderzoek mist een beschouwing over relevante veranderingen in de maatschappij die een toename van onterving van kinderen mogelijk teweegbrengen. Dat is jammer, want juist de maat-

17. Van Mourik, De legitieme portie: weg ermee! en Nuytinck, Het nieuwe erfrecht van Aruba, Curaçao en Sint Maarten.

18. Staten van de Nederlandse Antillen 2010, Landsverordening erfrecht en schenking, nr. 3 (MvT), I.6 (Algemeen).

19. Rapport, deel B, par. 10.

20. Antwoorden op Kamervragen van het lid Bergkamp (D66), Aanhangsel Handelingen II 2019/20, nr. 3922. schappelijke context is in de onderhavige discussie uitermate relevant.

In 2016 deden Beuker en Kolkman in opdracht van de Nederlandse vereniging voor Familie- en Erfrecht Advocaten Scheidingsmediators (vFAS) een onderzoek naar het aantal rechtszaken op erfrechtelijk gebied tussen 2003 en 2015. ${ }^{21}$ Daarvoor inventariseerden zij de op rechtspraak.nl gepubliceerde zaken. Het onderzoek indiceert dat het aantal rechtszaken op erfrechtelijk vlak de laatste jaren fors is toegenomen. ${ }^{22}$ Het onderzoek maakte onderscheid tussen verschillende categorieën erfrechtzaken. In een relatief bescheiden deel van alle erfrechtzaken stond de legitieme portie centraal (7\%). De meeste erfrechtzaken betroffen volgens de cijfers verdelingen van nalatenschappen/ontbonden huwelijksgemeenschappen (34\%), op afstand gevolgd door zaken rondom vereffeningen $(10 \%) .{ }^{23}$ De forse stijging van rechtszaken deed zich in alle categorieën voor.

In een interview in Trouw verklaart Kolkman de toename van het aantal erfrechtzaken vanuit het gegroeide vermogen van burgers en de toename van hun mondigheid. ${ }^{24}$ Latten (hoogleraar sociale demografie aan de Universiteit van Amsterdam) schrijft blijkens een interview in het Advocatenblad de toename van conflicten in het erfrecht vooral toe aan het feit dat men sinds 1971 gemakkelijk kan scheiden. ${ }^{25}$ Daarmee werd ook hertrouwen eenvoudiger, waardoor vaker sprake is van een 'tweede leg' en er problematische familieverhoudingen ontstaan. Vooral de kinderen uit een eerste huwelijk voelen zich benadeeld. De personen die sinds die tijd zijn gescheiden, de babyboomers, komen nu op leeftijd en hun nalatenschappen vallen steeds vaker open, aldus Latten. Ligt deze verklaring van Latten wellicht aan de basis van de toename van het aantal ontervingen? Hoewel mogelijk ook andere verklaringen denkbaar zijn, acht ik deze verklaring plausibel. Dit zou betekenen dat de toename van onterving van kinderen vooral te maken heeft met gebroken relaties van de testateur. De uiterste wil van de testateur/ouder moet dan, volgens tegenstanders van de legitieme, worden beschermd tegen aanspraken van kinderen uit voorbije relaties. Opgemerkt zij dat de wetgever de testateur daarin al in vergaande mate tegemoet is gekomen door hem de mogelijkheid te geven de legitieme portie, voor zover deze ten laste komt van zijn levenspartner, niet-opeisbaar te maken (art. 4:82

21. De gegevens van het onderzoek zijn niet meer te vinden op de site van vFAS. De onderzoekers verstrekten mij de gegevens zelf.

22. Opgemerkt zij dat niet alle rechtszaken op rechtspraak.nl gepubliceerd worden. Ook kan het zijn dat het in 2003 minder gebruikelijk was om uitspraken op rechtspraak.nl te plaatsen dan tegenwoordig het geval is. Er kan slechts gesproken worden van een grove indicatie.

23. In 2019 deden Beuker en Kolkman een vervolgonderzoek naar het aantal erfrechtzaken in 2016-2018. De gegevens hiervan ontving ik eveneens van de onderzoekers zelf. De conclusie van dit onderzoek is dat het aantal erfrechtzaken verhoudingsgewijs bij de rechtbanken stabiliseert en bij de gerechtshoven afneemt. Dit is in lijn met de algemene trend in het gehele civiele recht.

24. Zie de uitlatingen van W.D. Kolkman, in: J. Cornelissen, Erfenis? Dat leidt steeds vaker tot rechtszaken en familiebreuken, Trouw 10 november 2017.

25. Zie de uitlatingen van J. Latten, in: D. van Dijk, Erfrecht is booming business, Advocatenblad 2018, afl. 4, p. 26 en 27. 
BW). De vraag is dan of het wenselijk is dat de wetgever het erfrechtelijk afhouden van deze kinderen (nadat zij de leeftijd van 21 jaar hebben bereikt) volledig faciliteert, of dat het gerechtvaardigd is dat zij een weerwoord behouden in de vorm van een (vaak niet-opeisbare) legitieme portie.

\subsection{Belangen en toekomstige ontwikkelingen}

De hang naar erfrechtelijke autonomie lijkt vooral afkomstig uit de jaren zestig van de vorige eeuw. ${ }^{26}$ Het motto 'Ik mag toch zelf wel uitmaken aan wie ik mijn vermogen nalaat?' past bij een streven naar vrijheid van het individu en een zo min mogelijke bemoeienis vanuit de overheid. Op het eerste oog is dat streven lovenswaardig. Wie zijn autonomie goed weet te hanteren en besef heeft van verantwoordelijkheid kan er goed mee doen. Men kan er echter ook - al dan niet bewust of onder invloed van derden - bij zijn kinderen onrecht en leed mee aanrichten, door geen of onvoldoende rekening te houden met hun gevoelens. Het gaat bij het kind veelal niet alleen om de teleurstelling van niets of te weinig krijgen, maar vooral om het gevoel door zijn ouder(s) te zijn miskend.

De legitieme portie staat symbool voor het belang van de afstammingsband tussen ouders en kinderen. Het instituut weerspiegelt een norm die solidariteit van ouders naar hun kinderen niet volledig oplegt (onterven mag immers), maar wel zeer sterk benadrukt. Het kind dat zich door een erfrechtelijke benadeling mogelijk miskend voelt, kan met een beroep op zijn legitieme portie zijn leed verzachten. Dat de legitieme portie - in het geval zij niet opeisbaar is - soms slechts een symbolische waarde heeft, hoeft aan het gevoel van compensatie niet af te doen. De legitieme portie geeft daarnaast een waarschuwend signaal af aan de ouder die zijn kind wil onterven of benadelen. Voor de een voelt deze norm vooral als ernstige betutteling, voor de ander als volkomen gerechtvaardigd.

In de discussie rondom de legitieme portie gaat het enerzijds om het belang van bescherming van solidariteit van ouders naar kinderen en anderzijds om het belang van een zo groot mogelijke autonomie van een testateur. Bezien we deze idealen, dan is het niet vreemd dat de meningen over de legitieme portie zijn verdeeld en vermoedelijk ook verdeeld zullen blijven.

Maximale autonomie in het erfrecht is een ideaal dat sinds de jaren zestig onmiskenbaar aan populariteit heeft gewonnen. Het gaat niet per se om een verlicht ideaal, waarvan de populariteit geen grenzen kent. Men kan zich in deze discussie - ondanks een toename van ontervingen van kinderen door hun ouders - ook afvragen of dit ideaal niet al zijn beste tijd heeft gehad.

Belangrijk in dit kader is de vraag hoe de economische ontwikkelingen de komende decennia zullen zijn. Er zijn verschillende tekenen dat het de toekomstige generatie minder voor de wind zal gaan dan de huidige. $Z o$ is het kopen van een huis voor starters nu al hast onbereik-

26. Dit neemt niet weg dat op de legitieme portie daarvóór ook al kritiek werd geleverd. De kritiek is van alle tijden. Zie hierover Kolkman, De legitieme portie, met bijbehorende verwijzingen. baar. Opleidingskansen staan mogelijk in de toekomst minder garant voor succes dan voorheen, een uitzicht op pensioen is minder rooskleurig en grote wereldproblemen zorgen voor immense uitdagingen. De kloof tussen 'zij die hebben en zij die niet hebben' zou er ook wel eens een van generaties kunnen zijn. Deze ontwikkelingen kunnen juist het verlangen naar meer waarborgen voor solidariteit van ouders naar hun kinderen toe vergroten. ${ }^{27}$

\section{Peilingen}

\subsection{Peilingen onder het Nederlands publiek}

In deel $\mathrm{A}$ van het onderzoeksrapport staan de peilingen centraal. Er zijn peilingen uitgevoerd onder het Nederlands publiek (op drie verschillende manieren) en onder (kandidaat-)notarissen, erfrechtadvocaten en andere professionele dienstverleners.

Meest interessant is de peiling onder het Nederlands publiek. Er zijn drie verschillende peilingen gehouden, een online enquête, een onderzoek op basis van straatinterviews en peilingen uitgevoerd door Motivaction.

De belangrijkste vraag die in elk van de onderzoeken werd gesteld is: 'Kinderen hebben wettelijk gezien altijd recht op een minimum (legitieme portie) van de erfenis van hun ouder, of die ouder nou wil of niet, vindt $u$ dat terecht?' Op het antwoord op deze vraag zijn namelijk de belangrijkste conclusies van het rapport gebaseerd. Van de deelnemers aan de drie bovengenoemde peilingen geven respectievelijk 32\%, 48\% en 44\% aan de stelling terecht te vinden. Respectievelijk 43\%, 27\% en $22 \%$ geven aan de stelling niet terecht te vinden. In alle onderzoeken vindt $6 \%$ de stelling terecht, maar alleen als de kinderen minderjarig of jongmeerderjarig zijn. Respectievelijk 14\%, 10\% en 10\% van de deelnemers vinden dit ook, maar met de toevoeging: 'en dan alleen voor zover nodig voor opvoeding, levensonderhoud en studie'. Respectievelijk 5\%, 9\% en 3\% vinden de stelling terecht, maar alleen als de kinderen behoeftig zijn/ onder het bestaansminimum zitten op het moment van overlijden. Alleen het onderzoek van Motivaction kende een categorie weet niet/geen mening, die door $15 \%$ van de deelnemers is aangekruist. ${ }^{28}$

Dat respectievelijk 32\%, 48\% en $44 \%$ van de deelnemers in deze peiling ervoor voelen de legitieme portie te handhaven, acht ik met de onderzoekers aannemelijk. De onderzoekers zijn echter te kort door de bocht met hun conclusie dat respectievelijk 43\%, 27\% en 22\% van de deelnemers helemaal af millen van de legitieme portie. ${ }^{29}$ Dat is immers niet de stelling die hun is voorgelegd. Ik constateer dat zij het slechts niet eens zijn met de stelling dat kinderen altijd een recht hebben op de legitieme portie. Ze kregen niet de ruimte aan te geven

27. Zie hierover B. Sirks, De legitieme portie, AA 2013, afl. 11, p. 874, die zich afvraagt of solidariteit met de volgende generatie niet eerder tot herstel van een reële legitieme moet leiden.

28. Zie Rapport, deel A, par. 2.2.

29. Zie Rapport, deel A, par. 3. 
wat zij mel rechtvaardig vinden. Ik kan mij bijvoorbeeld voorstellen dat een gedeelte van degenen die 'niet terecht' aankruisten het niet terecht vindt dat een kind aanspraak maakt op zijn legitieme portie als het zich jegens zijn ouders heeft misdragen. Dat al deze deelnemers voor een compromisloze afschaffing zijn, waag ik zeer te betwijfelen. Zij kiezen in ieder geval niet voor de aanbeveling van de onderzoekers, die de legitieme portie willen afschaffen, maar de som ineens van artikel 4:35 BW (in aangepaste vorm) willen behouden, want daarvoor kiezen slechts respectievelijk 14\%, 10\% en $10 \%$ van de deelnemers.

Het legitiemevraagstuk is mijns inziens moeilijk met algemene vragen voor het Nederlands publiek invoelbaar te maken. Denkbaar is dat het publiek in bepaalde gevallen goed mee kan voelen met de legitimaris en een beroep op de legitieme portie volledig gerechtvaardigd vindt, maar in andere gevallen veel meer sympathie heeft voor de testateur. Een peiling waarin de deelnemers op casusniveau bevraagd zouden zijn, had interessante inzichten kunnen geven. Gedacht kan worden aan de volgende vragen:

a. Stel: een ouder onterft zijn kinderen uit een verbroken relatie. Vindt $\mathrm{u}$ het over het algemeen terecht dat deze kinderen aanspraak kunnen maken op een legitieme portie?

b. Stel: een kind verbreekt na een ruzie het contact met zijn ouders. Vindt $u$ het over het algemeen terecht dat dit kind bij overlijden van de ouders nog aanspraak kan maken op een legitieme portie?

c. Stel: een ouder onterft zijn verstandelijk gehandicapte kind. Vindt $\mathrm{u}$ het over het algemeen terecht dat namens dit kind aanspraak gemaakt kan worden op een legitieme portie, zodat de lasten die met het kind gemoeid zijn niet volledig worden afgewenteld op de Staat?

d. Stel: een man heeft een kind verwekt, maar nooit erkend. Kort na het overlijden van de man weet het kind via de rechter alsnog een afstammingsband te krijgen met de man. Het kind blijkt onterfd te zijn. Vindt $\mathrm{u}$ het over het algemeen terecht dat dit kind aanspraak kan maken op een legitieme portie?

e. Stel: een man heeft tot op zijn sterfbed een uitstekende band met zijn kinderen. Na zijn overlijden blijkt hij zonder enige vorm van overleg zijn hele vermogen naar een goed doel te hebben vermaakt. Vindt $\mathrm{u}$ het over het algemeen terecht dat deze kinderen aanspraak maken op een legitieme portie?

f. Stel: een agrariër laat zijn hele vermogen na aan zijn zoon die het bedrijf voortzet. Vindt $u$ het over het algemeen terecht dat zijn overige kinderen, die niets krijgen en niets hebben gehad, aanspraak kunnen maken op een legitieme portie?

Er zijn ongetwijfeld meer vragen te bedenken die het legitiemevraagstuk beter invoelbaar maken. Om de sfeer rondom de beleving van de legitieme portie daadwerkelijk te proeven was het ook interessant geweest binnen het kader van het wetenschappelijk onderzoek ervaringsdeskundigen te horen. Ik doel dan enerzijds op tes- tateurs die hun kinderen willen onterven en gefrustreerd zijn over de legitieme portie, en anderzijds op kinderen die zich geconfronteerd zagen met een onterving. ${ }^{30}$

\subsection{Peilingen onder professionals}

Onder professionals zijn ook peilingen gedaan. Aan notarissen werd dezelfde hoofdvraag voorgelegd als aan het Nederlands publiek. Aan de erfrechtadvocaten en andere professionals werd rechtstreeks de vraag gesteld of zij van mening zijn dat de legitieme portie moet worden afgeschaft. Opmerkelijk is het verschil in antwoorden tussen (kandidaat-)notarissen enerzijds en advocaten anderzijds. Waar de meeste (kandidaat-)notarissen $(76 \%)$ zich tegen handhaving van de legitieme portie uitspreken, zijn de meeste advocaten (70\%) juist tegen afschaffing. Van de andere professionals, bestaande uit fiscaal adviseurs, financieel planners en executeurs, is de meerderheid (69\%) voor afschaffing. De uitslag wekt de vraag op in hoeverre het beroep dat de professionals uitoefenen hun mening beinvloedt.

De notaris is sinds 1 oktober 1999 meer een ondernemer geworden en richt zich noodzakelijkerwijs meer dan voorheen op de wensen van zijn cliënt en (daardoor) minder op het algemeen maatschappelijk belang. Op erfrechtelijk vlak bedient hij doorgaans de testateur en bij de afwikkeling van nalatenschappen de erfgenamen, die hem bij de aanvang van de afwikkeling benaderen met het verzoek om een verklaring van erfrecht. Incidenteel wordt hij bij de afwikkeling van een nalatenschap geconfronteerd met een legitimaris die aanspraak maakt op een legitieme portie. De notaris kan dan een bemiddelende rol spelen en ervoor zorgen dat de afwikkeling niet escaleert. Het neemt niet weg dat de legitieme portie niet in het belang is van het overgrote merendeel van de cliënten in zijn erfrechtelijke praktijk: de erfgenamen en degenen die een testament maken.

Een testateur wil doorgaans er zo veel mogelijk van gegarandeerd zijn dat zijn laatste wens verwezenlijkt wordt. Vaak is dat mede de wens dat zo min mogelijk (liefst geen) erfbelasting wordt betaald. Veel testamenten die worden gemaakt in het kader van estateplanning impliceren een schending van de legitieme portie. Denk bijvoorbeeld aan testamenten gebaseerd op de tweetrapsmaking (de zogenaamde Radar-testamenten), die niet bedoeld zijn om kinderen uiteindelijk het familievermogen te onthouden, maar om het vermogen op een voor de langstlevende partner zo voordelig mogelijke wijze te doen overgaan. Hetzelfde geldt als gebruik wordt gemaakt van zogenaamde afvullegaten, waarbij de erfdelen van de kinderen worden verkleind tot het voor de erfbelasting vrijgestelde bedrag. De legitieme portie is een stoorzender bij het maken van dergelijke testamenten. Een 100\%-garantie voor een vlekkeloze uitwerking van de opzet kan de notaris immers niet geven. De legitieme portie zorgt ook voor wrijving bij de overdrachten van bedrijven van ouders op het kind dat

30. Op de website www.legitiemeportie.com nodigen de onderzoekers het publiek uit om een mening te geven over de legitieme portie. Tussen de meningen treft men een aantal sprekende opmerkingen aan van personen die aangeven ervaring te hebben met het onderwerp. 
het bedrijf voortzet. Het blijft nodig ook andere kinderen bij een rimpelloze overdracht te betrekken, al wil de testateur anders. De fiscaal adviseur, estateplanner en executeur zijn eveneens voornamelijk in de eerste plaats dienstbaar aan de belangen van de testateur.

Erfrechtadvocaten zullen regelmatig verongelijkte legitimarissen als hun opdrachtgevers ontmoeten. Een erfrechtadvocaat zal zich vermoedelijk veel vaker dan de (kandidaat-)notaris of estateplanner moeten inleven in zijn standpunt met bijbehorende emoties.

In het beroep dat de professionals uitoefenen, lijkt dus mede de verklaring voor hun opvatting te schuilen. Ik betwijfel of zij vanwege hun professie geheel onafhankelijk kunnen angeven met welk standpunt de rechtspraktijk het meest is gediend. Het spreekwoord 'wiens brood men eet, diens woord men spreekt' zal in iedere beroepsgroep in zekere mate opgeld doen. Voor de discussie rondom het bestaansrecht van de legitieme portie kan daarom beter waarde gehecht worden aan de peiling onder het publiek. De uitkomst hiervan kan voor de beoefenaars van bovengenoemde beroepen wellicht aanleiding zijn voor bezinning op de vraag of hun eigen opvatting nog voldoende aansluit bij hetgeen men in de maatschappij vindt of ervaart.

De mening van (kandidaat-)notarissen, advocaten en andere professionals vanuit hun persoonlijke situatie bezien blijkt volgens de peilingen te verschillen van hun opvatting als beroepsbeoefenaar. De legitieme portie is dan bij alle beroepsgroepen vanuit hun privésituatie bezien minder populair. Dit geldt dus ook voor (kandidaat-)notarissen, bij wie de legitieme portie vanuit hun beroepsperspectief gezien al niet populair was. Dat is een opmerkelijke constatering. Een verklaring hiervoor is niet gegeven (er is ook niet naar gevraagd).

\section{Conclusie}

Uit het Nijmeegse onderzoek naar de legitieme portie valt op te maken dat de meningen over de wenselijkheid van de legitieme portie onder het Nederlands publiek zijn verdeeld. Dat is niet nieuw. De populariteit van opvattingen kan fluctueren, maar het onderzoek toont niet overtuigend aan dat de gangbaarheid van de opvatting dat we de legitieme portie kunnen missen de laatste jaren is gegroeid. Een groot deel van de deelnemers aan de peiling neigt naar handhaving van de legitieme portie, terwijl een ander groot deel naar afschaffing of aanpassing neigt. Daarbij is (buiten de in de peiling genoemde categorieën om) niet geheel duidelijk wat onder 'aanpassing' wordt verstaan. De conclusie in het onderzoeksrapport dat de deelnemers die het niet terecht vinden dat kinderen zich altijd op een legitieme portie kunnen beroepen helemaal af willen van de legitieme portie, is veel te kort door de bocht. Het is jammer dat er in de peiling geen casusgerichte vragen zijn gesteld.

Het is duidelijk dat bij zowel (kandidaat-)notarissen als estateplanners, fiscaal adviseurs en executeurs de legi- tieme portie aanzienlijk minder populair is dan bij het publiek. Bij erfrechtadvocaten blijkt de sympathie voor de legitieme portie juist groter. Dit lijkt vooral iets te zeggen over de beroepsgroepen. Zo valt een afkeer van de legitieme portie bij (kandidaat-)notarissen (mede) te verklaren vanuit de toegenomen marktwerking in het notariaat, waardoor zij zich meer op de wens van hun cliënten (testateurs en erfgenamen) en de kwaliteit van hun producten zijn gaan richten. Voor veel van hun cliënten is de legitieme portie vooral een storende factor. De sympathie voor de legitieme portie onder erfrechtadvocaten valt juist te verklaren vanuit het feit dat zij regelmatig de legitimaris als cliënt bijstaan. Dit relativeert de waarde van de uitslag van de peilingen onder de beroepsgroepen in sterke mate.

De cijfers in het rapport rechtvaardigen de aanbeveling om de legitieme portie af te schaffen niet. Zij bevestigen juist eerder de keuze die de wetgever in 2003 heeft gemaakt om de testeervrijheid voorop te stellen en de legitieme portie op belangrijke punten te ontkrachten.

Bezien wij de maatschappelijke ontwikkelingen, dan is aannemelijk dat familiebanden losser zijn geworden. Huwelijken eindigen vaker in scheidingen, die soms ook leiden tot breuken tussen ouders en kinderen. Het is goed denkbaar dat de gesignaleerde toename van ontervingen van kinderen vooral te maken heeft met de toename van deze scheidingen. Met een onterving wordt de breuk tussen ouder en kind eenzijdig, door de ouder, bezegeld. Breuken tussen ouders en kinderen zijn - door wie ook veroorzaakt - pijnlijk en onwenselijk. Testeervrijheid staat sinds 2003 voorop, maar als de legitieme portie in dit kader de testateur kan aanzetten tot bezinning, is handhaving al zinvol.

De legitieme portie is een hanteerbare anspraak, omdat deze buiten de rechter om kan worden verwezenlijkt. De rechter oordeelt niet over het motief van de testateur om een kind te benadelen, maar ook niet over het motief van een kind om zijn legitieme portie in te roepen. Dat maakt dat de legitieme portie te verkiezen kan zijn boven een alternatief waarbij rechterlijke tussenkomst wel nodig is. Een zwak punt van de legitieme portie is dat het recht ook geldt in gevallen waarin dit vanuit objectief oogpunt niet rechtvaardig is. Gedacht kan worden aan de situatie waarin een kind zich naar zijn ouders toe ernstig heeft misdragen. De lat voor onwaardigheid (art. 4:3 BW) ligt dan wel erg hoog.

Met het afschaffen van de legitieme portie wordt alleen het belang van de testateur gediend, met het risico dat de balans in het erfrecht verstoord raakt. Dat lijkt mij ongewenst. De wetgever doet er daarom goed aan de legitieme portie met rust te laten. Nadere nuancering van de legitieme portie, waar zij (in objectieve zin) onrechtvaardig uitpakt, is voorstelbaar, mits zij niet ten koste gaat van de hanteerbaarheid van de regeling. ${ }^{31}$

31. Zie voor enkele suggesties voor eventuele vereenvoudiging van de regeling van de legitieme portie overigens T.J. Mellema-Kranenburg, Tien jaar nieuw erfrecht, TE 2013, afl. 6, p. 103-106. 